Brit. J. vener. Dis. (1961), 37, 197.

\title{
SYPHILITIC PAROXYSMAL COLD HAEMOGLOBINURIA
}

\section{A CASE REPORT*}

BY

\author{
E. E. PREBBLE
}

Royal Infirmary, Liverpool

Paroxysmal cold haemoglobinuria is a comparatively rare condition and a number of cases have been described in which there was an associated syphilitic infection.

Malley and Hickey (1949) described a patient with a non-syphilitic paroxysmal cold haemoglobinuria in whom the Wassermann and the Donath-Landsteiner reactions were negative. Haematological investigation showed the presence of chronic haemolytic anaemia. A high-titre cold agglutination was constantly present in the patient's serum and there was increased susceptibility of the patient's red cells to mechanical trauma. Death occurred and was due to urinary obstruction and ascending urinary infection.

Nichols and Williams (1949) reported a patient with a history of primary syphilis 16 years previously which was inadequately treated with arsphenamines. For the past 7 years he had been subject during the winter months to attacks of paroxysmal cold haemoglobinuria, the symptoms of which were shaking chills followed by fever, sweats, nausea, vertigo, and the passage of darkly-coloured urine, and 5 months before admission he had developed symptoms of general paralysis of the insane. He was treated with penicillin which brought about considerable improvement in his mental condition and there was no recurrence of paroxysmal cold haemoglobinuria even after exposure to freezing cold. These authors observed that few patients suffering from paroxysmal cold haemoglobinuria had any clinical manifestations of syphilis.

Suckling (1951) reported paroxysmal cold haemoglobinuria in a boy aged 6 years with congenital syphilis. He had positive Wassermann and DonathLandsteiner reactions with haemoglobinuria, anaemia, and reticulocytosis, and an enlarged liver and

\footnotetext{
- Received for publication October 28, 1960
}

spleen. Two other members of his family were syphilitic but neither they nor the rest of the family suffered from haemoglobinuria.

Jordan, Pillemer, and Dingle (1951) described two patients. The first was a female aged 30 years who had had eight to ten attacks in the past four winters, usually after a walk to the bus stop and a long wait for the bus. The condition was apparently cured by injections of bismuth and penicillin. The patient's husband also had a positive Wassermann reaction. Their second patient, a male aged 27 years, had two attacks whilst working out of doors in cold weather. He was given $7 \cdot 2$ mega units penicillin and $1,500 \mathrm{ml}$. blood was replaced by $1,200 \mathrm{ml}$. of the same type. In spite of this treatment the attacks continued.

Hill (1951) reported a patient aged 80 years, suffering from gummata in the lung and liver, who developed gastro-intestinal bleeding and was given a blood transfusion, the blood not being heated to room temperature. After $100 \mathrm{ml}$. had been transfused he developed a shaking chill followed by a rise in temperature to $102^{\circ} \mathrm{F}$. Cold agglutinins were present in the recipient's blood to a titre of $1 / 320$. The DonathLandsteiner reaction was found to be positive for cold-warm haemolysins. The following day he was given warmed blood without any ill effects; he improved and was discharged, but 17 months later cold agglutinins were present in a dilution of $1 / 20$ and Donath-Landsteiner reaction showed no evidence of cold-warm haemolysins.

Peterson and Walford (1952) described a patient aged 47 years with a long history of attacks of paroxysmal cold haemoglobinuria. He was found to have a positive Wassermann reaction and a typical paretic fluid and was lethargic and mentally dull. He was treated with penicillin and ACTH with some improvement. Two apparently separate haemolysins were observed in this patient: cold haemolysin which 
was responsible for the Donath-Landsteiner reaction, and an acid haemolysin which was a thermolabile antibody requiring a lower $\mathrm{pH}$ for the production of haemolysis.

Jordan (1952) stated that a more sensitive DonathLandsteiner test did not detect the haemolysin of paroxysmal cold haemoglobinuria in sera of patients with syphilis more often than tests used in other surveys, and further that, although related to syphilitic infection, paroxysmal cold haemoglobinuria antibody was shown to differ from treponemal immobilizing antibody, the specific antibody of syphilitic infection. He concluded that the mechanism of production of paroxysmal cold haemoglobinuria antibody remained unexplained.

Baxter and Jordan (1954) described a patient with 7 years' history of paroxysmal cold haemoglobinuria who failed to respond to a number of courses of penicillin.

Rosenblum and Cetnar (1954) reported a patient, a native of Hawaii, who was treated for congenital syphilis and who developed paroxysmal cold haemoglobinuria when exposed to cold weather during service in Korea. The Wassermann reaction and cardiolipin test were found to be negative. No further treatment was given and he was finally discharged by a medical board. In this case attacks recurred in spite of adequate anti-syphilitic therapy with penicillin and heavy metals.

Watson and Laurie (1956) described a case in a Bantu male aged 32 years who passed dark-coloured urine on getting up each morning for 7 consecutive days. At first this was considered to be a case of nocturnal haemoglobinuria but it was found that the patient became cold during the night, and that he had had a previous attack 10 months earlier, during cold weather. He received 9 mega units of penicillin in one week with improvement.

\section{Case Report}

An apparently healthy male aged 47 years complained that for the past 2 years, after exposure to cold, he had a number of shivering attacks followed by passing blood-stained urine.

He had been married for 10 years. Both his parents had died at the age of 81 years and he had one brother and two sisters alive, all of whom were older than he.

He was admitted to hospital in April, 1957, for investigation, and the blood-stained urine was found to be due to haemoglobin.

Haematology

$\mathrm{Hb}: 69$ per cent. (10.1 g./100 ml.).

Reticulocytes: 3.3 per cent.

Direct Coombes test at $37^{\circ} \mathrm{C}$.: Negative.

Induced Coombes test at $22^{\circ} \mathrm{C}$.: Positive.

Donath-Landsteiner antibody: Present to a titre of 1/8. No other cold or warm haemolysins detected.
Warm complete or incomplete agglutinins: Not detected.

Incomplete cold antibody: Present to a titre of 1/16 at $22^{\circ} \mathrm{C}$.

Complete cold antibody titres: Within normal limits.

48-hr haemolysis test at $37^{\circ} \mathrm{C}$.: Within normal limits.

Wassermann reaction: Positive 1/64.

Meinicke reaction: Strongly positive.

Treponemal Wassermann reaction: Positive.

Price's precipitation reaction: Positive.

Treponemal immobilization test: Positive.

There was no history of syphilis and no clinical signs of the disease. During May and June, 1957, he received 16.8 mega units PAM. In September, 1957, the Wassermann reaction was positive $1 / 32$, and during October and November he received a further course of 16.8 mega units PAM. On December 13, 1957, he developed haemoglobinuria, and had a further attack about 4 weeks later. These were the only attacks which occurred during the winter months and were unaccompanied by shivering. He had marked clubbing of the fingers and gave a history of Raynaud's disease in previous years but had been free of this since starting anti-specific treatment.

In February, 1958, the blood Wassermann reaction was positive $1 / 2$, but by March, 1958, the titre had risen to 1/128. During March, April, and early May, he received 18 mega units PAM. He had a mild attack of haemoglobinuria in April, 1958. In September, 1958, the Wassermann reaction was positive $1 / 64$, and during October and November, 1958, he received 19.2 mega units PAM. One further slight attack occurred in the November and this was the last attack experienced to date.

The Wassermann reaction has since fluctuated between positive $1 / 64$ and $1 / 16$ and he has been given two further courses of PAM.

\section{Diagnosis}

The diagnosis of the condition usually presents little difficulty. The history is suggestive and the finding of haemoglobinuria helps to establish the diagnosis.

Apart from the usual diagnostic tests, there are several comparatively simple ways of arriving at a diagnosis:

(1) Mackenzie "Rough" Test.-A sample of the patient's blood is chilled in iced water. A positive test is denoted by haemolysis after the blood is warmed

(2) Ehrlich's Test.-The finger is bound with a ligature and immersed in ice water for a few minutes. After the finger is warmed, local haemoglobinaemia can be demonstrated.

(3) Rosenbach Test.-The hands or feet are immersed in iced water for 10 to 20 minutes. The resulting haemolysis may produce severe constitutional symptoms and has occasionally resulted in anuria. 


\section{Summary}

The literature on paroxysmal cold haemoglobinuria is surveyed, and a detailed report is presented of a patient suffering from this condition. Treatment of latent syphilis was followed by complete clinical recovery from the attacks.

\section{REFERENCES}

Baxter, J. A., and Jordan, W. S., Jr. (1954). Proc. Soc. exp. Biol. (N.Y.), 85, 648.

Hill, N. P. (1951). Amer. J. Syph., 35, 329.

Jordan, W. S. Jr. (1952). Proc. Soc. exp. Biol. (N.Y.), 80, 357.

Pillemer, L., and Dingle, J. H. (1951). J. clin. Invest., 30, 11.
Malley, L. K., and Hickey, M. D. (1949). Lancet, 1, 387. Nichols, F. T., and Williams, C. J. (1949). J. Amer. med. Ass., 140, 1322.

Peterson, E. T., and Walford, R. L. (1952). Blood, 7, 1109. Rosenblum, R., and Cetnar, E. J. (1954). A.M.A. Arch. intern. Med., 93, 304.

Suckling, P. V. (1951). S. Afr. med. J., 25, 238.

Watson, K. C., and Laurie, W. (1956). Ibid., 30, 1001.

\section{Hémoglobinurie paroxystique a frigore syphilitique}

\section{RÉSUMÉ}

L'auteur passe en revue la littérature de l'hémoglobinurie paroxystique $a$ frigore due à la syphilis et en décrit un cas. Le traitement de la syphilis latente entraîna la cessation complète des attaques. 